\title{
GAMAESPECTROMETRIA INTEGRADA A DADOS EXPLORATÓRIOS MULTIFONTE EM AMBIENTE SIG APLICADA À PROSPECÇÃO DE OURO NA FOLHA BOTUVERÁ, SC
}

\author{
LUIZ FORNAZZARI NETO \& FRANCISCOJOSÉ FONSECA FERREIRA
}

\begin{abstract}
GAMASPECTROMETRY INTEGRATED WITH MULTI-SOURCE EXPLORATORY DATA IN SIG ENVIRONMENT APPLIED TO GOLD EXPLORATION IN THE BOTUVERA QUADRANGLE, SC The research concerns gold exploration involving integration of 1:50.000 data from several sources in the area of Botuverá, Santa Catarina, Brasil $\left(27^{\circ} 00^{\prime}-27^{\circ} 15^{\prime} \mathrm{S}, 49^{\circ} 00^{\prime}-\right.$ $49^{\circ} 15^{\prime} \mathrm{W}$ ). The regional geological setting is marked by sin-late intrusion of the Valsungana/Guabiruba metaluminous to peraluminous and calc-alkaline to alkaline granitoids into the metamorphic rocks of the Brusque Complex. The studied area bears the most important occurrences of gold in Western Santa Catarina State, specially the filonean gold occurrences at Morro do Carneiro Branco (MCB), Braço da Cristalina and Tigrano. Data from geological and metalogenetic mapping of the Botuverá region and from the Serra do Mar Sul airborne gamma-ray spectrometric, form a georreferenced database that was processed and integrated using AutoCad, ArcView, Er-Mapper and Geosoft software packages. With special emphasis being placed on the gamma-ray spectrometric images and profiles, the airborne responses of $\mathrm{K}$, eTh and $\mathrm{eU}$ and their relationships in $\left(\mathrm{eTh} / \mathrm{K}, \mathrm{eU} / \mathrm{eTh}\right.$ and $\mathrm{eU} / \mathrm{K}, \mathrm{F}=\mathrm{K}^{*} \mathrm{eU} / \mathrm{eTh}$, and Th-normalized of the $\mathrm{K}$ and $\mathrm{eU}$ anoamlies), it was possible to determine new exploration targets from the radiometric signatures of known occurrences. From the integration of the geophyisical, geological, Landsat/TM5 imagery and morphostructures derived from digital terrain modeling data and results achieved in a GIS environment, three new exploration targets are determined in Botuvera Region.
\end{abstract}

Keywords: Exploratory integrated data, gamma-ray spectrometry, geoprocessing, gold exploration.

Resumo A pesquisa envolveu a integração de dados exploratórios de fontes diversas, com enfoque gamaespectrométrico prospectivo para ouro, na região da Folha Botuverá-SC, escala 1:50.000, limitada pelas coordenadas $27^{\circ} 00^{\prime}$ e $27^{\circ} 15^{\prime}$ de latitude sul e $49^{\circ} 00^{\prime}$ e $49^{\circ} 15^{\prime}$ de longitude oeste. O contexto geológico é marcado por rochas metamórficas do Complexo Brusque e corpos granitóides intrusivos sin a tardi-tectônicos, cálcio-alcalinos a alcalinos, conhecidos como Valsungana e Guabiruba. Aárea encerra as mais importantes ocorrências de ouro da região leste catarinense, com destaque aos filões de quartzo do Morro do Carneiro Branco (MCB), Braço da Cristalina e Tigrano. Os dados disponíveis, geológicos e metalogenéticos da Folha Botuverá e gamaespectrométricos do Projeto Aerogeofísico Serra do Mar Sul (1978), constituiram a principal base digital de dados georreferenciados. Tais dados foram processados e integrados através de ferramentas disponíveis nos programas AutoCad, ArcView, ER Mapper e Geosoft. Priorizando-se os dados gamaespectrométricos foram geradas imagens de $\mathrm{K}$, eTh e eU e de suas razões (eTh/K, eU/eTh e eU/K), Parâmetro F=K*eU/eTh, além de anomalias de K e eU normalizadas pelo eTh. Estes parâmetros também foram avaliados através de perfis, aproveitando-se da maior densidade de dados ao longo das linhas de vôo, o que permitiu discriminar as principais unidades geológicas e proceder a comparação entre os diversos maciços granitóides em termos do grau de alteração hidrotermal (sericitazação) e do potencial para ouro, com base nas respostas das principais ocorrências. Estes resultados, integrados em ambiente SIG aos demais dados geofísicos, geológicos, de imagens Landst-5/TM e do modelo digital de elevação (MDE), possibilitaram propor três novos alvos exploratórios para ouro na Folha Botuverá.

Palavras-chave: Integração de dados exploratórios; gamaespectrometria; geoprocessamento, prospecção de ouro.

INTRODUÇÃO A exploração mineral envolve procedimentos de coleta, análise e integração de dados oriundos de várias fontes. A integração digital de dados geológicos, geofísicos, geoquímicos, de sensoriamento remoto e de outras informações georreferenciadas voltada à prospecção mineral, atualmente é realizada através de software e hardware específicos, aproveitando o grande avanço das geotecnologias presenciado nas duas últimas décadas. Assim, os Sistemas de Informações Geográficas (SIG) surgem como um conjunto de técnicas matemáticas e computacionais para o tratamento da informação georreferenciada, as quais permitem o gerenciamento de dados espaciais com realização de análises complexas, facilitando a tomada de decisões.
Tais avanços são igualmente marcantes no campo dos métodos geofísicos, em especial os magnetométricos e gamaespectrométricos. Tem sua contribuição aumentada pela facilidade de integração com dados de outras naturezas, como geológicos, geoquímicos e de relevo, estes últimos representados por Modelo Digital de Elevação (MDE), além de imagens orbitais do tipo Landsat/TM.

A gamaespectrometria, tradicionalmente utilizada como apoio ao mapeamento geológico regional e à prospecção mineral de urânio, experimentou avanços importantes nos últimos anos. Recentemente, a introdução de gamaespectrômetros de alta resolução e a transformação das contagens por segundo (cps) em \% de K, eU 
(urânio equivalente) e eTh (tório equivalente) em ppm, acompanhada por um notável avanço das técnicas de geoprocessamento em ambiente SIG e dos sistemas de processamento digital de imagens, além do posicionamento por satélite (Global Positioning System - GPS), tem permitido extrair informações valiosas dos dados gamaespectrométricos em correspondência à integração de dados exploratórios multifonte. Uma das aplicações modernas da gamaespectrometria é a possibilidade de identificar áreas de alteração hidrotermal e estabeler suas relações com processos de mineralização de metais base $(\mathrm{Cu}-\mathrm{Pb}-\mathrm{Zn})$, além de ouro e prata em vários ambientes geológicos (e.g. Shives et al. 2000).

A pesquisa possui caráter metodológico e enfoca uma série de ferramentas utilizadas na prospecção mineral, com ênfase na gamaespectrometria, com o objetivo principal de testá-las no estudo de mineralizações de ouro filoneano e na determinação de áreas favoráveis à sua ocorrência na Folha Botuverá-SC, situada entre as coordeandas $27^{\circ} 00^{\prime}$ e $27^{\circ} 15^{\prime}$ 'de latitude sul e $49^{\circ} 00^{\prime}$ e $49^{\circ} 15^{\prime}$ ' de longitude oeste. Para tanto almejamos os seguintes objetivos intermediários: 1) Comparar, na área de estudo, os dados gamaespectrométricos originais do Projeto Aerogeofísico Serra do Mar Sul (CPRM 1978) com aqueles reprocessados pelo Brazil Airborne Radiometric Mapping Project (BARMP 1997), os quais envolveram micronivelamento e transformações das contagens por segundo (cps) para ppm de eU e eTh e \% de K, através de retrocalibração; 2) Avaliar o potencial do método gamaespectrométrico na caracterização de áreas de alteração hidrotermal associadas a ocorrências de ouro e propor novos alvos exploratórios.

CONTEXTO GEOTECTÔNICO As primeiras modelagens geotectônicas realizadas por Hasui et al. (1975), caracterizaram a região de estudo como pertencente à Província Mantiqueira, Setor Meridional, subdividida localmente de noroeste para sudeste em: a) Maciço Mediano de Joinville, incluindo os terrenos gnáissico-granulíticos da região de Luís Alves; b) Sistema Dobrado Tijucas, correspondente ao Complexo Brusque e granitóides e c) Maciço Mediano de Pelotas, relacionado ao complexo graníticognáissico. Estes terrenos, exceto o Maciço de Joinville, constituem o Cinturão Dom Feliciano definido por Fragoso-César (1980) e dividido por Basei (1985) em Domínio Externo (Bacia do Itajaí), Domínio Intermediário (Complexo Brusque) e Domínio Interno (Maciço Mediano de Pelotas).

O Complexo Brusque é limitado por duas grandes zonas de falha de direção NE-SW, uma a sul denominada zona de cisalhamento Major Gercino e a outra a norte conhecida como zona de cisalhamento Perimbó. Ressalta-se ainda uma zona de falha interna, denominada Itajaí-Mirim, com disposição geral na mesma direção. Soares (1988) interpretou o Grupo Brusque como uma associação litológica e metamórfica originada no Proterozóico Médio, com a deformação e o metamorfismo impostos por colisão de blocos crustais em torno de 1000-800 Ma e 700-500 Ma. Este autor ainda associou o granitóide Valsungana a um magmatismo gerado em torno de $650 \mathrm{Ma}$, relacionado ao evento colisional neoProterozóico do tipo I, com contribuição mantélica adquirida em ambiente de arco magmático. Basei (1996) considerou para a evolução geológica da região uma colisão dextral oblíqua (ca. 535 $\mathrm{Ma}$ ), relacionada às nappes do Grupo Brusque, com sentido de deslocamento para NW, refletindo provavelmente os esforços gerados entre o domínio costeiro e os metassedimentos do Grupo Brusque ao longo da zona de cisalhamento Major Gercino. Soares et al. (2000) concluiram que a evolução dos cinturões Dom Feliciano e Ribeira é bastante similar, tanto do ponto de vista tectônico e metamórfico, quanto da evolução de suas bacias sedimentares, pré-sin-, tardi- e pós-colisionais. Basei et al. (2000) realizaram uma síntese do conhecimento da região, onde avaliaram que o contexto geológico foi marcado por uma evolução ocorrida durante a transição neo-Proterozóico/Cambriano e uma reativação durante o Mesozóico, responsável pela abertura do oceano Atlântico Sul. Para estes autores o evento compressivo neo-Proterozóico/ Cambriano (orogêneses Brasiliano e Rio Doce) envolveu dois domínios tectônicos principais representados pelo Cinturão Dom Feliciano e sua região de ante-país (Cráton Luis Alves).

\section{GEOLOGIAEASPECTOS METALOGENÉTICOSDAFOLHA}

BOTUVERÁ-SC A Folha Botuverá está inserida na porção central do embasamento pré-Ordoviciano do estado de Santa Catarina, com um núcleo do embasamento remobilizado; um cinturão metavulcano-sedimentar do Proterozóico Inferior-Médio, com direção geral N50E (Complexo Brusque); uma cobertura vulcano-sedimentar (Bacia do Itajaí) e granitóides do Neoproterozóco/Eo-Paleozóico. O Complexo Brusque e os granitóides nele intrudidos são as principais unidades da área (Fig. 1) e de maior interesse à prospecção ouro. A Bacia de Itajaí, que ocorre na porção noroeste, e a faixa do embasamento que a separa dos metamorfitos daquele complexo compreendem cerca de um $1 / 3$ da área.

De acordo com o mapa da figura 1, o Complexo Brusque agrupa as seguintes unidades principais com caráter litofaciológico: 1) MPA1 - unidade siliciclástica pelítico-arenosa (filitos e filitos grafitosos); 2) MPA2 - unidade siliciclástica pelítico-arenosa (micaxistos e quartzitos micáceos granatíferos); 3) MCC - unidade carbonática (metacalcários, subordinadamente metapelitos, metabásicas porfiríticas e xistos magnesianos); 4) MVS - unidade vulcano-sedimentar (metabásicas porfiríticas e xistos magnesianos, subordinadamente metagabros, metabasaltos finos e variolíticos, metapelitos, metarritmitos pelítico-arenosos e metacalcários); 5) MAP - unidade siliciclástica areno-pelítica (metarritmitos pelíticoarenosos). Ainda ocorrem corpos filoneanos ácidos e básico-intermediários do Eopaleozóico, bem como diques de diabásio e de rochas alcalinas mesozóicas. Depósitos aluvionares distribuemse ao longo dos vales dos principais rios, como aqueles do rio Itajaí-Mirim.

Os corpos granitóides intrudidos no Complexo Brusque são conhecidos como Faxinal (biotita-hornblenda sienito a sienomonzogranito, quimismo metaluminoso, alcalino, do tipo A); Suíte Valsungana/Guabiruba (sieno e monzogranitos a granodioritos, quimismo dominantemente metaluminoso a peraluminoso, cálcialcalinos a alcalinos, gerados a partir de fonte mista) e fácies Indaiá (monzogranitos, sieno-granitos e granodioritos). Praticamente todos os corpos pertencentes às suítes afetaram termicamente as rochas encaixantes, gerando zonas de hornfels bem desenvolvidas (Fig. 1).

As informações metalogenéticas para ouro (Caldasso et al. 1995) indicam as ocorrências em rocha e aluviões, zonas e estações anômalas em pintas de concentrados de bateia e áreas favoráveis para mineralizações auríferas, conforme a figura 2 .

As ocorrências foram plotadas com a seguinte numeração: 1 Morro do Carneiro Branco (filões de quartzo com Au e Ag); 2 Braço da Cristalina (filões de quartzo+volframita+ouro); 3 - Tigrano (filões de quartzo aurífero); 4 - Russo; 5 - Três Barras, 6-Gaspar Alto e 7-Quati (filões de quartzo aurífero encaixados na Bacia de Itajaí). Para concentrados de bateia os referidos autores conside- 


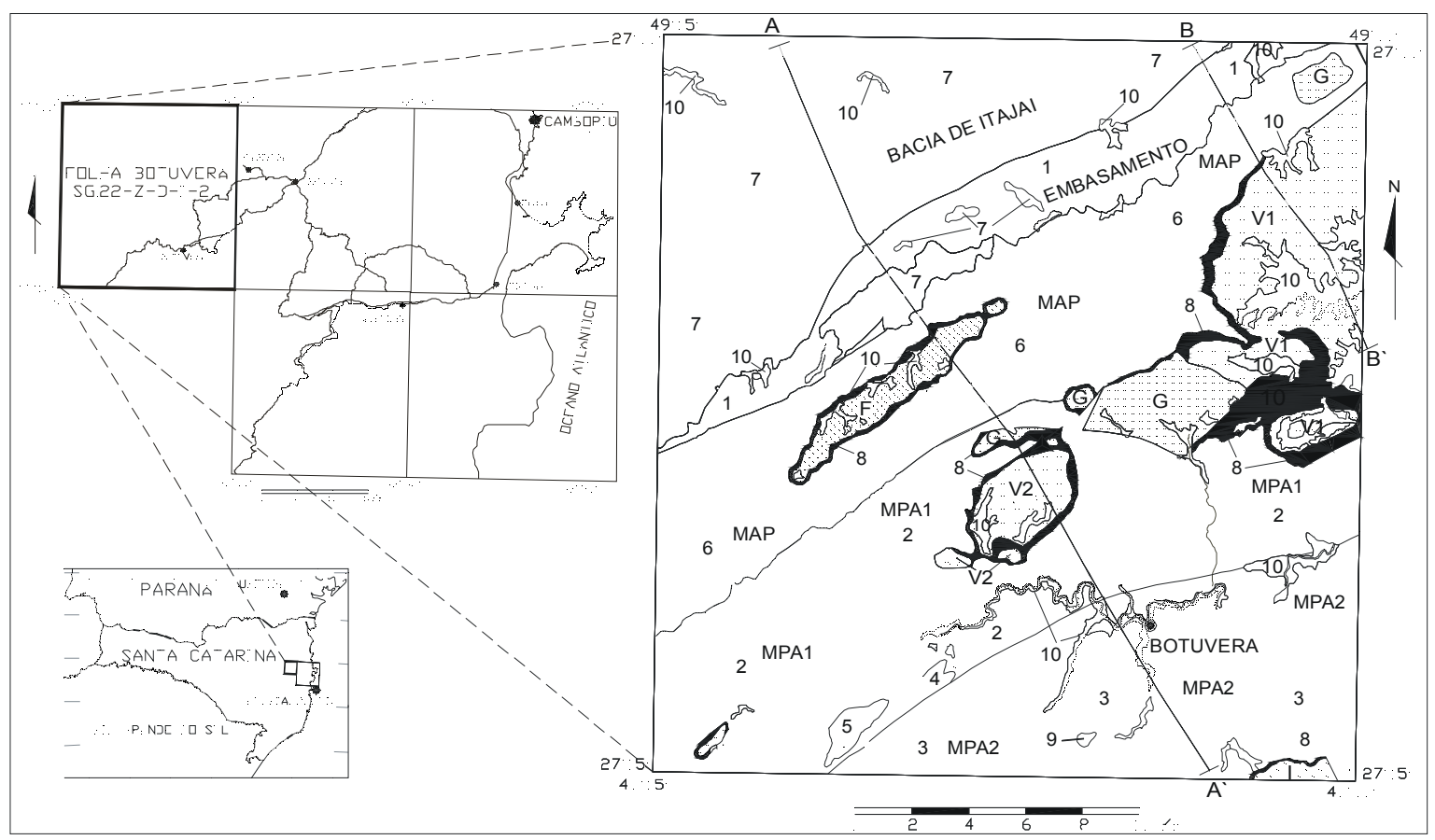

Figura 1 - Mapa geológico da Folha Botuverá-SC (simplificado de Caldasso et al. 1995), indicando os perfis aerogamaespectrométricos/geológicos (AA' e BB' conforme figura 10): Arqueano/Gnaisses (1); Proterozóico Inferior-Médio/ Complexo Brusque: MPA1 (2), MPA2 (3), MCC (4), MVS (5), MAP (6); Proterozóico Superior: Seqüência Vulcano-Sedimentar Itajai (7) e Granitóides (F - Faxinal; G - Guabiruba; V1 - Valsungana 1; V2 - Valsungana 2; I - Indaiá); Hornfels (8) Rochas Alcalinas (9); Aluviões, eluviões e tálus (10).

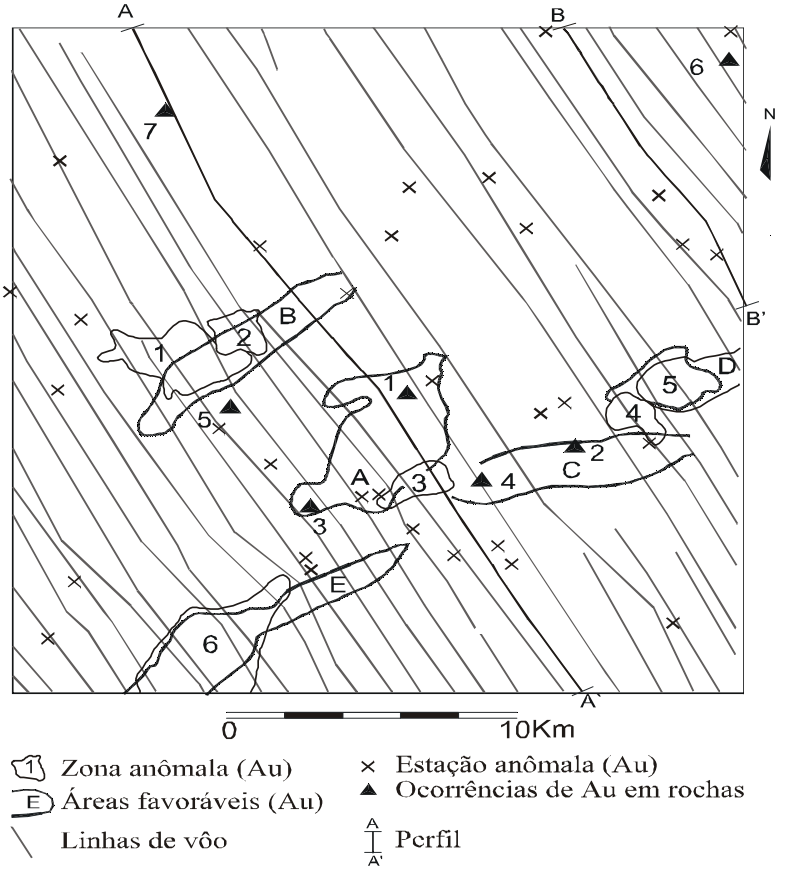

Figura 2 - Ocorrências de ouro, áreas favoráveis, zonas e estações anômalas em pintas de concentrados de bateia da Folha Botuverá-SC (modificado de Caldasso et al. 1995), indicando as linhas de vôo e os perfis gamaespectrométricos/geológicos (AA'e $B B$ ' conforme figura 10). raram estações anômalas aquelas bacias onde foram identificadas mais de 5 partículas de ouro, enquanto as zonas anômalas foram definidas pelo agrupamento de duas ou mais estações anômalas contíguas. As áreas favoráveis para mineralizações de ouro são representadas na figura 2 da seguinte maneira: a) mineralização aurífera filoneana na periferia dos corpos granitóides (ocorrências do MCB e do Tigrano); b) periferia e porção central do granitóide Faxinal; c) filões de quartzo associados a volframita e ouro (ocorrências do Braço da Cristalina e do Russo); d) corresponde à zona anômala 5 (granitóide Valsungana); e) vinculada à zona anômala 6 .

Quanto aos teores, os veios do sistema NE-SW apresentam concentrações mais elevadas, alcançando até 14,5 ppm nas porções mais sulfetadas e oxidadas, onde ocorrem texturas boxwork com ouro visível, e não inferiores a 1,8 ppm nos pontos com poucos sulfetos. Também existem sulfetos disseminados na rocha encaixante, nas proximidades dos veios, constituindo guia para a prospecção. Os veios do sistema NS, encaixados nos granitóides, apresentam teores de 0,8 e 2,6 ppm em amostras de canal com aspecto textural diferente dos demais. A zona de contato entre os granitóides e os metassedimentos exibe teores de até 35,2 ppm e superiores a $2 \mathrm{ppm}$. Além de ouro ocorre também prata com concentrações que variam de 0,2 ppm a 13,6 ppm, dosadas por cianetação, com máximo de 33,3 ppm determinado por absorção atômica.

A região do Morro do Carneiro Branco é acidentada e o principal alvo (MCB) é constituído por uma zona de veios de quartzo sulfetados de direção geral E-W, posicionada na borda norte do granitóide Lageado Alto do fácies Valsungana. Com espessura média de $2 \mathrm{~m}$, atingindo até $5 \mathrm{~m}$, aflora descontinuamente por 
aproximadamente $200 \mathrm{~m}$, com teores médios de $6 \mathrm{~g} /$ ton e pontualmente até $23 \mathrm{~g} /$ ton de ouro associado a prata, cobre, arsênio e bismuto, este último subordinado.

DADOS AEROGEOFÍSICOS O Projeto Aerogeofísico Serra do Mar Sul (CPRM 1978), realizado a uma altura média de vôo de 150 $\mathrm{m}$ e espaçamento entre as linhas em torno de $1.000 \mathrm{~m}$, exibe uma densidade de uma amostra à cada $56 \mathrm{~m}$ ao longo das linhas de vôo dispostas segundo a direção N30W-S60E. As leituras gamaespectrométricas foram realizadas por um sensor multiespectral modelo DIGRS-3001, da Exploranium, acoplado a um conjunto de cristais de iodeto de sódio ativado a tálio, totalizando $1.017,87$ polegadas cúbicas e com tempo de integração de 1 segundo.

Os dados radiométricos foram micronivelados (Minty 1991) e convertidos de contagens por segundo (cps) para concentrações (\% de K, ppm de eU e de eTh) e $\mu \mathrm{R} / \mathrm{h}$ (taxa de exposição, dose), para o canal de contagem total, com base em procedimentos de retrocalibração (BARMP 1997). Os valores das constantes de calibração foram os seguintes: Tório $(\mathrm{eTh})-\mathrm{cps} / \mathrm{ppm}=1,78$; Potássio $(\mathrm{K})$ - cps/ppm = 25,88 e Urânio (eU) - cps/ppm = 10,07.

Os dados anteriores a este processamento foram avaliados por Silva \& Mantovani (1994), os quais constataram e quantificaram a distribuição dos erros de posicionamento, atribuindo-os à complexidade operacional e às características geomorfológicas e climáticas regionais. Apesar dos problemas mencionados, alguns exemplos bem sucedidos da aplicação destes dados, tanto no auxílio ao mapeamento geológico quanto à prospecção mineral, foram relatados por Ferreira \& Algarte (1979), Fornazzari Neto et al. (1996), Castro (1997), Ferreira \& Stevanato (1998), Ferreira \& Silva (1999), Castro et al. 2002 (neste volume), entre outros.

GAMAESPECTROMETRIA O processamento, a análise e a interpretação dos dados gamaespectrométricos foram norteados por conceitos e técnicas ainda pouco difundidos no ambiente da exploração mineral no Brasil, como análises de unidades geológicas e de perfis (Graham \& Bonham-Carter 1993; Nabi 1995). Concentraram-se esforços numa abordagem mais detalhada quanto possível, no tratamento de tais dados, a fim de caracterizar o comportamento dos radioelementos e avaliar suas relações com as mineralizações de ouro da área estudada, no sentido de determinar guias prospectivos e sugerir novos alvos exploratórios conforme apresentado na figura 3 .

Dentre os trabalhos radiométricos mais importantes da literatura aplicados à prospecção de ouro, destacam-se, segundo Dickson \& Scott (1997), as experiências de pesquisadores russos, os quais estudaram as relações entre os radionuclídeos nos diversos ambientes mineralizados. Ao revisarem tais trabalhos, constataram que as assinaturas gamaespectrométricas de depósitos de ouro são muito variáveis, porém o enriquecimento de potássio normalmente constitui guia para a localização indireta de concentrações auríferas. Apesar das mineralizações em geral ocorrerem em veios de quartzo, as rochas encaixantes, hidrotermalizadas, podem ser detectadas através de halos potássicos. Uma revisão anterior (Hoover \& Pierce 1990), também apontou para a importância do potássio nos processos hidrotermais em áreas mineralizadas. Tais processos são marcados por grande interação fluido-rocha, com lixiviação de alguns elementos e concentração de outros em sistema físico-químico aberto com reações de troca (metassomatismo), os quais imprimem modificações mineralógicas, texturais e químicas nas rochas afetadas. Sistemas hidrotermais ocorrem em diver-

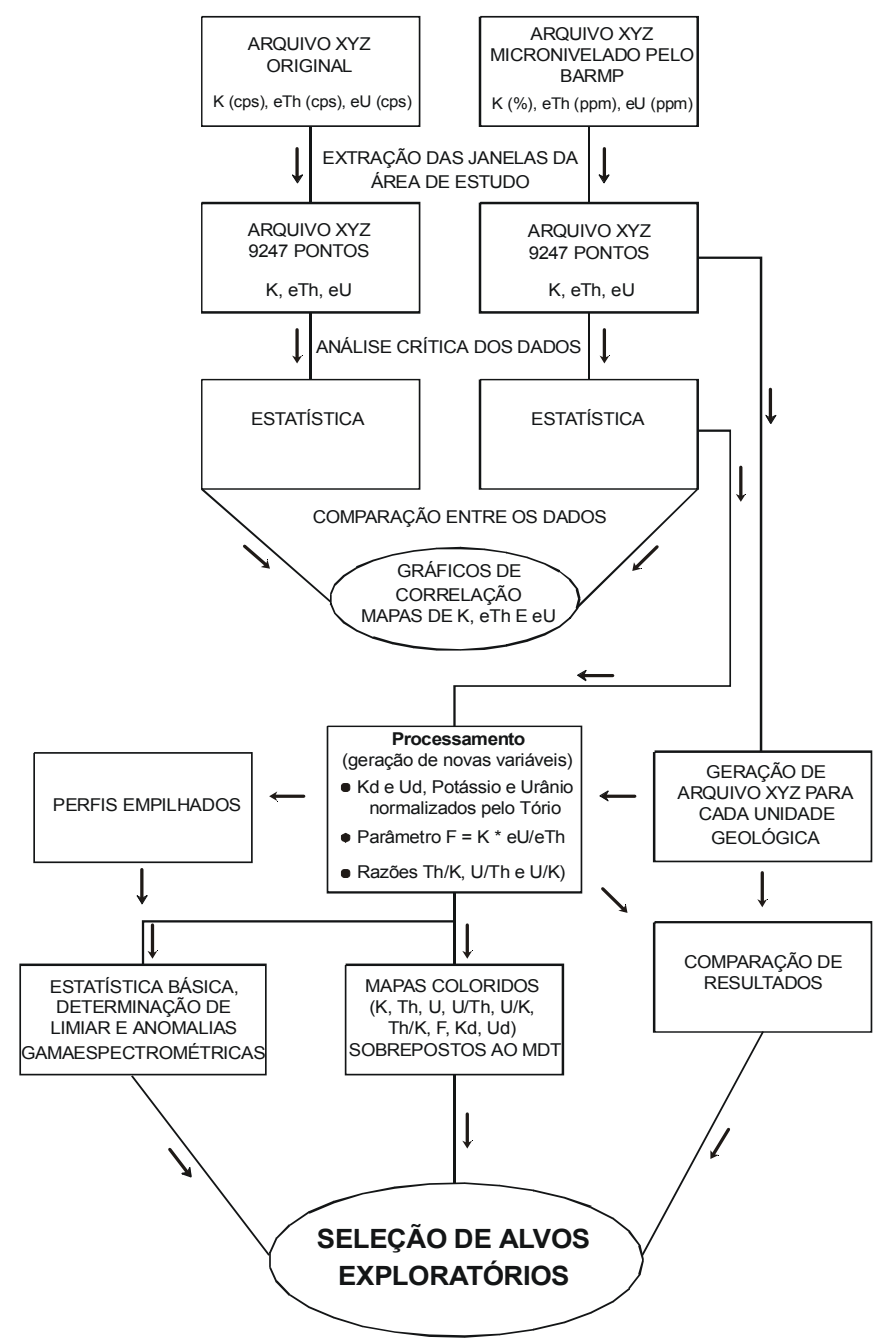

Figura 3 - Fluxograma de processamento dos dados gamaespectrométricos.

sos ambientes geológicos e são responsáveis por vários de tipos de depósitos minerais (Pirajno 1992). Dentre as formas de alteração hidrotermal duas apresentam importantes concentrações de $\mathrm{K}$, a potássica e a fílica. O urânio pode acompanhar o potássio nos processos hidrotermais, enquanto o tório, geoquimicamente menos móvel, apresenta comportamento oposto (antagonismo entre tório e potássio de Ostrovsky 1975).

Efimov (1978 apud Gnojek \& Prichystal 1985), propôs uma série de relações entre os radioisótopos, destacando que a expressão $\mathrm{K}^{*} \mathrm{eU} / \mathrm{eTh}$, denominada parâmetro $\mathrm{F}$, permite ressaltar o enriquecimento de potássio e urânio em relação ao tório, podendo indicar áreas com alteração hidrotermal associadas a mineralizações. As primeiras aplicações deste parâmetro em corpos granitóides no Brasil foram realizadas por Pascholati (1990) e Ferreira (1991).

Os teores dos radioelementos podem ser susceptíveis a efeitos ambientais, pedogenéticos, geomorfológicos, geoquímicos e variações litológicas (Dickson \& Scott 1997; Wilford et al. 1997). Segundo Saunders et al. (1987), o tório, que apresenta menor mobilidade geoquímica, pode ser usado como controle litológico para definir valores ideais de potássio e urânio de cada amostra, para posteriormente suprimir tais efeitos. Assim, propuseram uma 
normalização do potássio e do urânio pelo tório, aplicada à prospecção de petróleo, calculada da seguinte forma:

$\mathrm{K}_{\mathrm{i}}=\left(\right.$ média de $\mathrm{K}_{\mathrm{s}} /$ média de $\left.\mathrm{Th}_{\mathrm{s}}\right) \times \mathrm{Th}_{\mathrm{s}} ; \mathrm{K}_{\mathrm{d}}=\left(\mathrm{K}_{\mathrm{s}}-\mathrm{K}_{\mathrm{i}}\right) / \mathrm{K}_{\mathrm{i}}$

$\mathrm{U}_{\mathrm{i}}^{1}=\left(\right.$ média de $\mathrm{U}_{\mathrm{s}}^{\mathrm{s}} /$ média de $\left.\mathrm{Th}_{\mathrm{s}}^{\mathrm{s}}\right) \times \mathrm{Th}_{\mathrm{s}}^{\mathrm{s}} ; \mathrm{U}_{\mathrm{d}}^{\mathrm{d}}=\left(\mathrm{U}_{\mathrm{s}}^{\mathrm{s}}-\mathrm{U}_{\mathrm{i}}^{1}\right) / \mathrm{U}_{\mathrm{i}}$, onde $\mathrm{K}_{\mathrm{i}}$ e $\mathrm{U}_{\mathrm{i}}$ indicam os valores ideais definidos a partir do tório, $\mathrm{K}_{\mathrm{d}}$ e $\mathrm{U}_{\mathrm{d}}$ são os desvios dos valores ideais e $\mathrm{K}_{\mathrm{s}}$ e $\mathrm{U}_{\mathrm{s}}$ representam os dados originais.

Pires (1995) empregou pela primeira vez este método na prospecção mineral, identificando com sucesso zonas de alteração hidrotermal em Crixás-Guarinos no estado de Goiás, através do potássio anômalo $\left(\mathrm{K}_{\mathrm{d}}\right)$. Após esta experiência novas aplicações desta técnica, em conjunto com o Parâmetro $\mathrm{F}$, foram relatadas por Ferreira et al. (1998), Blum (1999), Carvalho (1999), Quadros (2000), Biondi et al. (2001), Cainzos (2001), Fornazzari et al. (2001a), dentre outros.

Análise crítica dos dados Inicialmente foram extraídas janelas correspondentes à área de estudo, dos arquivos digitais originais e dos transformados por BARMP (1997), com o objetivo de compará-los e verificar sua pertinência para a presente pesquisa. Tais janelas abrangeram 9.247 amostras cada, distribuídas ao longo de 37 linhas de vôo, onde notou-se variações no espaçamento entre as linhas, chegando a $2.000 \mathrm{~m}$ na porção centro-oriental da área, além da interrupção de algumas delas (Fig. 2). O processamento para a geração de malhas regulares foi realizado no pacote Geosoft, pelo método da curvatura mínima (Briggs 1974). Foram testados diversos tamanhos de células, considerando as sugestões de Vasconcellos et al. (1990) e Luyendky (1997), segundo as quais sua dimensão ideal pode variar de 1/4 a 1/8 e 1/ 5 do espaçamento das linhas de vôo, respectivamente. Os mapas gerados com estas dimensões de células apresentaram falhas (vazios), em função da irregularidade no espaçamento das linhas de vôo. Assim, optou-se por uma malha regular de 750 x $750 \mathrm{~m}$ para minimizar tal problema.
Após a extração das referidas janelas as variáveis foram cotejadas por estatística básica, histogramas, mapas coloridos, perfis e gráficos de correlação. A comparação, quando realizada através de perfis, mostra que há uma correlação qualitativa entre os dados originais e os do BARMP (1997), notando-se nestes últimos uma nítida supressão dos sinais de alta freqüência espacial (Fig. 4).

$\mathrm{O}$ tratamento gamaespectrométrico consistiu na geração de novas variáveis, razões eTh/K, eU/K e eU/eTh, Parâmetro $\mathrm{F}=\mathrm{K} * \mathrm{eU} /$ eTh(Efimov 1978 apud Gnojek \& Prichystal 1985) e normalizações do potássio e do urânio pelo tório $\left(\mathrm{K}_{\mathrm{d}} \mathrm{e} \mathrm{U}_{\mathrm{d}}\right.$ de Pires 1995), as quais foram calculadas com base no banco de dados $x y z$, apesar da possibilidade de gerá-las também através das malhas regulares. Esta última alternativa foi descartada em função da suavização inerente ao processo de interpolação, além da irregularidade no espaçamento das linhas de vôo.

Análise de imagens As imagens gamaespectrométricas (Fig. 5) foram reamostradas com células de $30 \times 30 \mathrm{~m}$ e sobrepostas ao MDE, através do pacote ER Mapper, no sentido de verificar as distribuições dos teores em correspondência aos elementos de relevo, e observar possíveis dispersões dos radionuclídeos na paisagem oriundas de processos pedogenéticos e/ou de movimentos de massa (colúvios), como sugerido por Wilford et al. (1995).

Os maiores teores de potássio ocorrem principalmente segundo uma faixa diagonal (Fig. 5a), de sudoeste à nordeste, associados a porção setentrional da unidade MPA1 e aos granitóides Valsungana e Guabiruba. A Bacia de Itajaí apresenta valores altos e baixos, revelando diferenças em seu domínio. A faixa de embasamento, apesar de constituída por rochas de natureza granito-gnáissica, indica, no geral, baixos valores de potássio. A unidade MPA2 e o segmento mais pobre em potássio da unidade MPA1 apresentam comportamento similar ao da Bacia de Itajaí. O granitóide Faxinal e o extremo nordeste do corpo do fácies Guabiruba exibem baixos
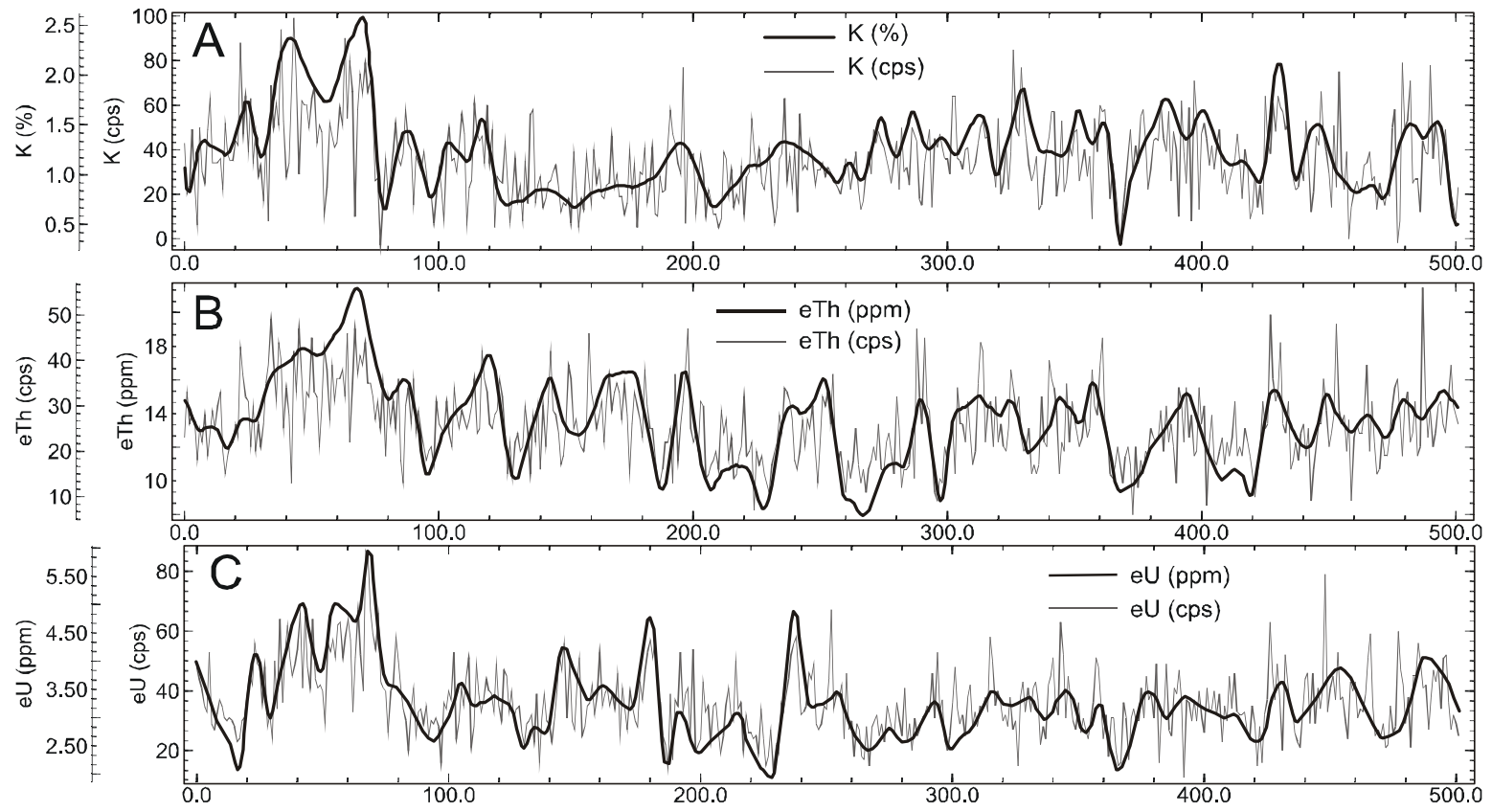

Figura 4 - Comparação entre perfis gamaespectrométricos originais (CPRM 1978), em cps, e transformados (BARMP 1997), em \% e ppm, respectivamente, nos scanais do $K(a)$, do eTh (b) e do eU (c). 
Gamaespectrometria integrada a dados exploratórios multifonte em ambiente SIG aplicada à prospecção de ouro na Folha Botuverá, SC
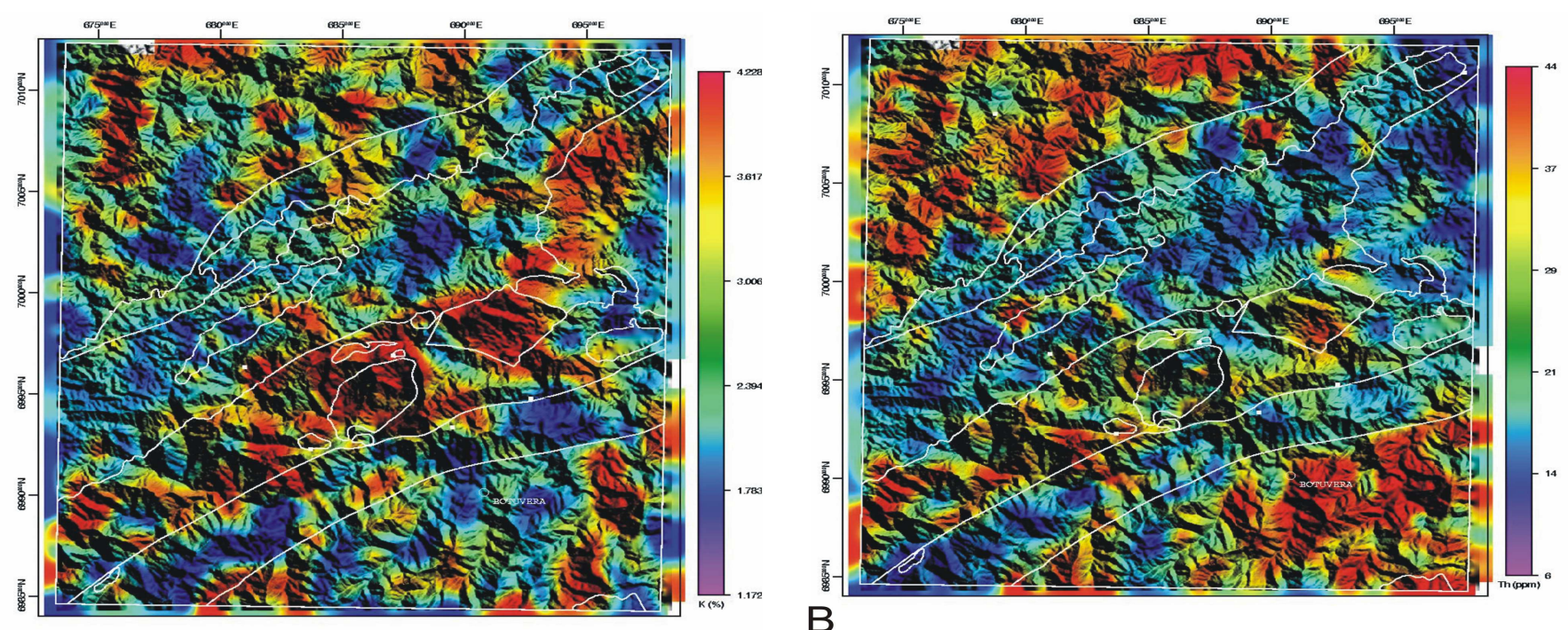

A
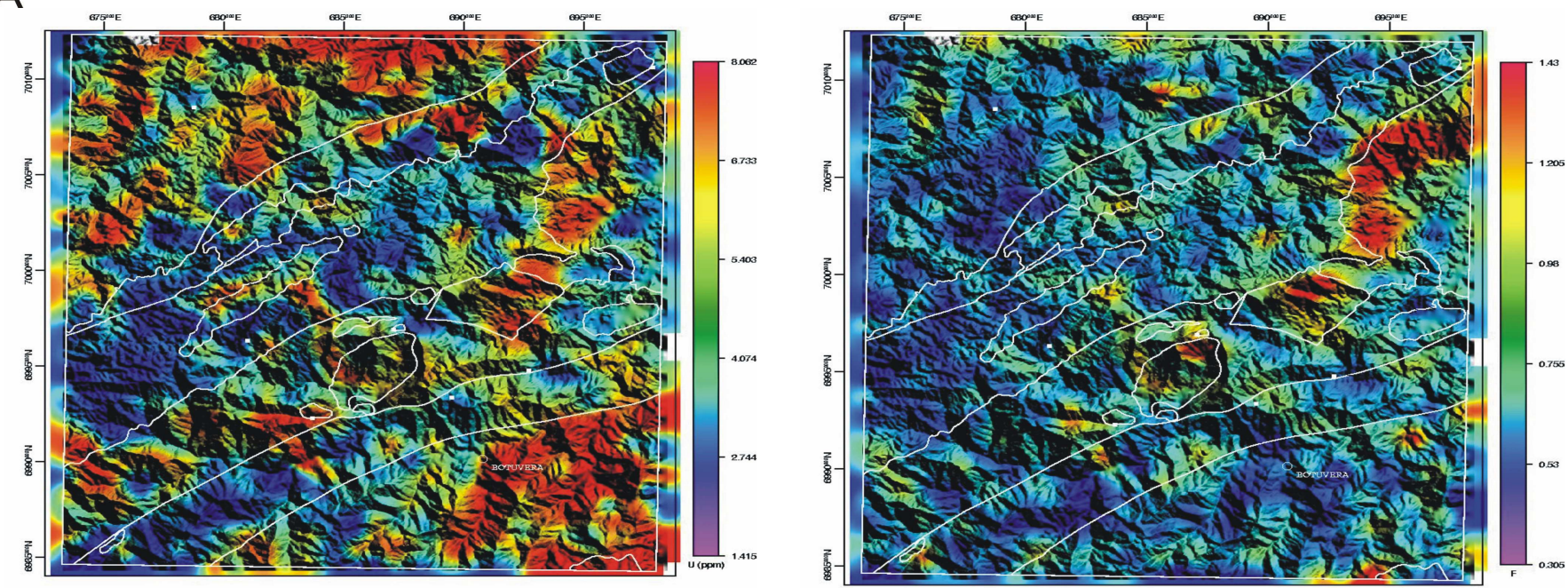

C

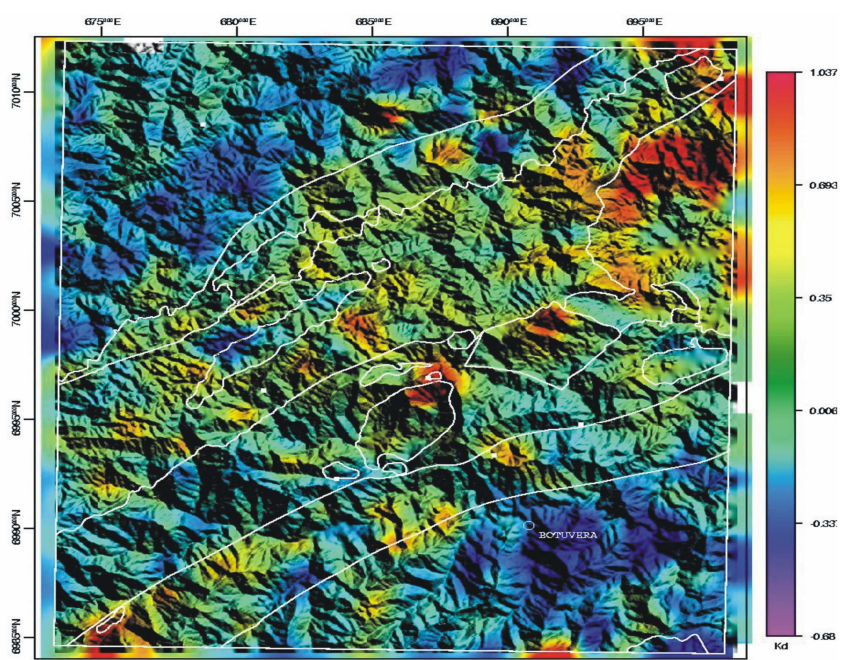

$\mathrm{E}$

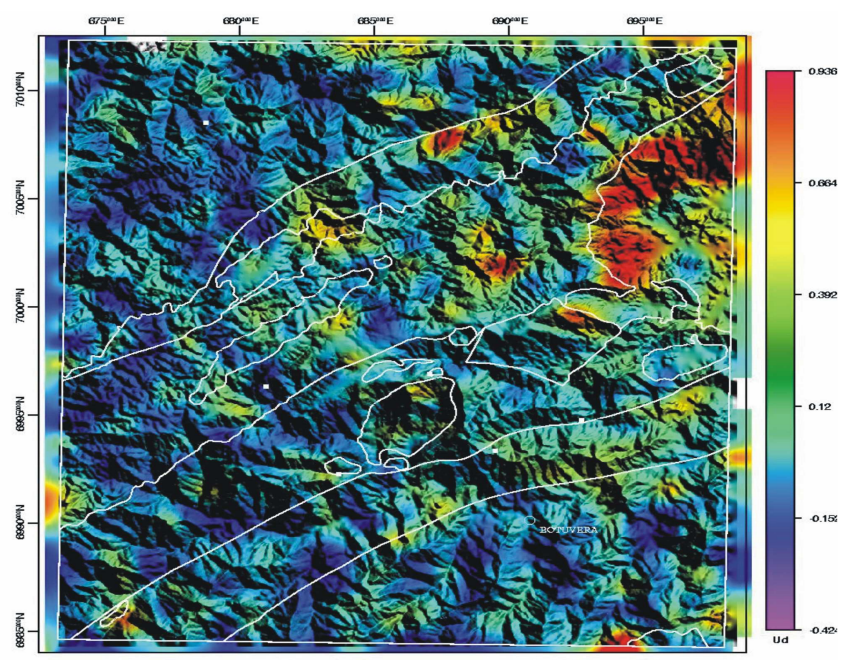

$\mathrm{F}$

Figura 5 - Imagens gamaespectroméricas da Folha Botuverá-SC sobrepostas ao MDE: Potássio (a), Tório (b), Urânio (c), Parâmetro $F(d), K_{d}(e)$ e $U_{d}(f)$. 
teores de $\mathrm{K}$.

A imagem do tório (Fig. 5b) permite distinguir claramente a Bacia de Itajaí da faixa de embasamento, com a qual faz contato. Esta faixa caracteriza-se-se por baixos teores com exceção de duas áreas em sua porção norte, uma em seu centro e a outra no contato com a Bacia de Itajaí. Quanto às unidades do Complexo Brusque, observa-se bom contraste entre as unidades MPA2 (altos teores) e MAP (baixas concentrações), enquanto que a unidade MPA1 apresentou a mesma diferenciação, conforme se nota na imagem do potássio (Fig. 5a). Os granitóides revelam baixos teores, em relação às demais unidades, com exceção de um corpo do fácies Guabiruba, porção centro-leste da área, e de um trato restrito localizado na borda oeste do granitóide Faxinal.

A distribuição do urânio (Fig. 5c) revela um comportamento mais homogêneo associado à unidade MAP do Complexo Brusque, caracterizado por baixo teores. Duas porções anômalas destacamse nesta unidade, nas bordas do granitóide Faxinal. Na Bacia de Itajaí e na unidade MPA2 ocorrem altas concentrações. Dentre os granitóides, o Guabiruba e o Valsungana apresentam altos índices de eU, em contraposição ao embasamento gnáissico. No interior da unidade MPA1 são assinalados altos teores ao longo do vale disposto segundo a direção $\mathrm{E}-\mathrm{W}$, em correspondência à porção oeste da ocorrência do Tigrano, de forma semelhante ao observado para o potássio.

Na imagem do Parâmetro F observou-se que os granitóides, de modo geral, apresentam altos valores de F com exceção do corpo Faxinal. Contudo, ao equalizar o histograma, as áreas com altos valores de $\mathrm{F}$ foram reduzidas, realçando as anomalias mais significativas em relação à totalidade da área (Fig. $5 \mathrm{~d}$ ). Tal processamento não acarretou prejuízos em função das demais análises realizadas (perfis empilhados com a topografia e a geologia). O granitóide Faxinal não apresenta anomalias, exceto em uma área restrita na sua borda leste situada no contexto dos metassedimentos da unidade MAP do Complexo Brusque. Toda a faixa ocidental do granitóide Valsungana é destacada por elevados valores de F. No Complexo Brusque assinala-se uma anomalia de pequena dimensão, cujo centro posiciona-se em um vale disposto segundo a direção $\mathrm{E}-\mathrm{W}$, localizado próximo a um pequeno corpo do fácies Valsungana e da ocorrência do Tigrano. No domínio da Bacia de Itajaí destaca-se com grande intensidade outra anomalia significativa, também de caráter restrito, possivelmente relacionada a intrusões riolíticas (Rostirolla, comunicação pessoal).

As imagens do $\mathrm{K}_{\mathrm{d}}$ e do $\mathrm{U}_{\mathrm{d}}$ com histogramas equalizados (Figs. 5e e 5f), separam a Bacia de Itajaí e a unidade MPA2 das demais rochas da faixa central da área, enquanto as anomalias destes parâmetros praticamente coincidiram com as do Parâmetro F (Fig. 5d).

Análise de unidades geológicas Os resultados estatísticos demonstraram que as distribuições são próximas à normal, ou pouco assimétricas, com exceção de $\mathrm{K}_{\mathrm{d}}$ e $\mathrm{U}_{\mathrm{d}}$, os quais revelaram desvios padrão muito superiores a média e coeficientes de variação $(\mathrm{CV})$ extremamente elevados. Como estas variáveis são de extrema importância prospectiva e dependentes das médias, a análise foi realizada por unidade geológica (Graham \& Bonham-Carter 1993; Nabi 1995; Stevanato 1998; Silva 1999), como é comum no tratamento de dados geoquímicos de exploração (separação de populações), por considerar que a mesma pode constituir parâmetro de comparação entre as unidades, facilitando a interpretação geofísico-geológica.

Neste intuito, o arquivo $(x y z)$ das variáveis $\mathrm{K}$, eU e eTh foi importado para o programa ArcView, onde cada amostra foi transformada em um ponto e associada a seus respectivos atributos (tema gamaespectrometria). Com as ferramentas de relacionamento, as amostras de cada unidade geológica (tema geologia, Fig. 1), digitalizadas e convertidas em polígonos, foram alocadas em novos arquivos. A partir deles, exportados em formato de tabela para o programa Excel, procedeu-se novamente os cálculos dos parâmetros $\mathrm{K}_{\mathrm{d}} \mathrm{e} \mathrm{U}_{\mathrm{d}}$. Em seguida os arquivos foram transferidos para o programa Statistics, no qual as operações básicas destas e de todas as demais variáveis foram realizadas. As médias de cada domínio são apresentadas na figura 6 , demonstrando as diferenças entre eles. Nota-se que as médias dos parâmetros $\mathrm{F}$ e $\mathrm{K}_{\mathrm{d}}$ são muito maiores nos granitóides, em comparação às demais unidades, como esperado em litologias com elevado background dos radionuclídeos.

Com o objetivo de refinar este método de discriminação gamaespectrométrica, os granitóides foram tratados separadamente e comparados entre si e em relação ao conjunto, segundo quatro grupos de acordo com a figura 1: Faxinal (F), Guabiruba (G) e Valsungana (V1 e V2). Os resultados obtidos ressaltaram as diferenças entre eles, onde foi constatado que o granitóide Faxinal mostrou a menor média de K (1,07\%) e de eU (3,25 ppm), enquanto para o eTh os valores situaram-se próximos aos demais. As unidades granitóides foram também avaliadas através de gráficos de correlação, o que permitiu visualizar as relações entre os pares como indicado na figura 7.

A figura 7a mostra a discriminação do granitóide Faxinal, caracterizado por altas razões $\mathrm{eTh} / \mathrm{K}$ (maior que 8 , com predomínio de índices superiores a 12) e baixo $\mathrm{F}$ (maioria entre 0,1 e 0,4 ), notando-se comportamento inverso em relação aos corpos Guabiruba (eTh/K entre 4 e 12 e F na faixa de 0,2 a 1,0). Na figura $7 \mathrm{~b}$, a suíte Guabiruba revela superposição entre índices de $\mathrm{Kd}$ (calculado para toda a área), entre - 0,5 e 0,5, e de F entre 0,1 e 0,6 . Entretanto, segmento significativo dos maciços Guabiruba são assinalados por valores de $\mathrm{Kd}$ (calculado para toda a área) e de F superiores a 0,5 e 0,6, respectivamente (Fig. 7b). É interessante notar que na figura $7 \mathrm{c}$, a separação entre estes maciços graníticos é mais nítida, praticamente eliminando os pontos de superposição, quando se confrontam $\mathrm{Kd}$ (calculado para cada granitóide) e F, em função da sensibilidade do $K_{d}$ (e também do $\mathrm{U}_{\mathrm{d}}$ ) às médias de $\mathrm{K}$, eU e eTh, as quais são distintas em cada corpo. Já os granitóides Valsungana 1 denotam grande variabilidade destes índices, em relação aos corpos Valsungana 2, o que sugere que os segmentos com baixas razões eTh/K $(<4)$ e elevados valores de $\mathrm{F}(>0,8)$ devem indicar a presença de tratos hidotermalizados (Fig 7d). Também observa-se nas figuras 7e e $7 \mathrm{f}$, o contraste de assinaturas gamaespectrométricas entre os corpos Valsungana 1 e 2 e, do mesmo modo, a confirmação da hipótese de especialização do corpo Valsungana 1, onde simultaneamente são registrados altos índices de $\mathrm{K}_{\mathrm{d}}$ (maiores que 1,5 e 0,8 , Figs. 7 e e $7 \mathrm{f}$, respectivamente) e de F (maiores que 0,8 ). Todavia, em função da similaridade petrográfica entre os mencionados corpos, os dados de $\mathrm{Kd}$ calculados para toda a área (Fig. 7e) e computados separadamente para cada granitóide (Fig. 7f), versus o Parâmetro F, revelaram assinaturas semelhantes nos tratos preservados do hidrotermalismo.

Este procedimento é relevante não somente porque possibilita discriminar corpos e unidades geológicas, mas também por permitir avaliar o comportamento dos radionuclídeos no interior de cada segmento, o que pode se constituir, por exemplo, em ferramenta auxiliar no mapeamento faciológico de maciços granitóides. Certamente, a qualidade do mapa geológico e a 

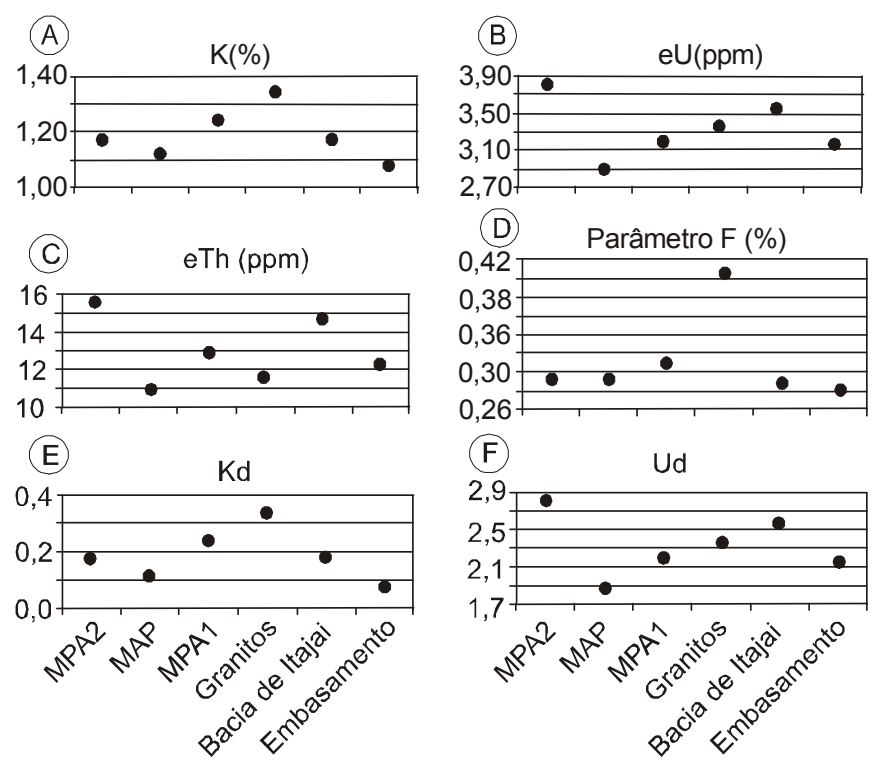

Figura 6 - Representação das médias gamaespectrométricas de unidades geológicas da Folha Botuverá-SC: Potássio (a), Urânio (b), Tório (c), Parâmetro $F(d), K_{d}(e)$ e $U_{d}(f)$.

precisão cartográfica dos contatos são fatores decisivos para um bom desempenho do método. Igualmente é importante para a prospecção mineral, uma vez que as anomalias relacionadas com alteração hidrotermal podem ser facilmente visualizadas e posicionadas em mapas e perfis empilhados com a geologia e a topografia, conforme será apresentado a seguir.

Análise de perfis Para a caracterização das anomalias primeiramente buscou-se localizar em planta, ao longo das linhas de vôo (Nabi 1995), as estações com valores elevados de F, $\mathrm{K}_{\mathrm{d}} \mathrm{e} \mathrm{U}_{\mathrm{d}}$. Através das estatísticas foram consideradas três faixas principais: a primeira com valores entre a média mais 1 e a média mais 2 desvios padrão; a segunda entre a média mais 2 e mais 3 desvios padrão e, por fim, índices maiores que a média mais 3 desvios padrão (Fig. 8), as quais foram selecionadas através da ferramenta de pesquisa query do ArcView.

Foram também construídos gráficos de correlação entre as variáveis gamaespectrométricas de maior interesse prospectivo (Fig. 9), no sentido de visualizar suas distribuições e indicar novos alvos exploratórios.

As 37 linhas de vôo foram analisadas separadamente, através de perfis empilhados, os quais foram relacionados com a geologia e a topografia, respectivamente extraídas do mapa geológico e do MDE. A figura 10 representa dois exemplos dos mencionados perfis, selecionados por encerrar anomalias. Os valores foram classificados nas categorias mencionadas e os resultados foram correlacionados com a geologia, ocorrências de ouro em rocha, concentrados de bateia, zonas anômalas e áreas favoráveis para em seguida sugerir novos alvos exploratórios.

A resposta gamaespectrométrica da área favorável $\mathrm{A}$, a qual envolve as ocorrências do MCB e do Tigrano (Fig. 11), foi estabelecida através dos perfis empilhados apresentados na figura 10a, em correspondência com o perfil geológico A-A'. Naquela ilustração observa-se claramente incrementos da razão eU/eTh, do Parâmetro F e das anomalias de $\mathrm{K}_{\mathrm{d}}$ e $\mathrm{U}_{\mathrm{d}}$. As anomalias destas últimas variáveis, acima da média mais três desvios padrão, também estão relacionadas com baixas razões $\mathrm{eTh} / \mathrm{K}$, todas indicativas de alteração hidrotermal, verificadas por ocasião da definição da assinatura gamaespectrométrica terrestre da ocorrência do MCB (Fornazzari et al.2001b).

A área favorável B, representada pelo granitóide Faxinal, não apresentou resposta indicativa de alteração hidrotermal, apesar das altas contagens de pintas de ouro em concentrados de bateia, sugerindo que os processos de mineralização devem ser distintos dos anteriores, ou seja, não estão relacionados com alteração hidrotermal potássica. A área favorável C não foi avaliada em função da falta de dados (grande espaçamento entre as linhas de vôo, ver figura 2).

$\mathrm{A}$ área $\mathrm{D}$, de forma parecida com à zona $\mathrm{B}$, não apresentou resposta compatível com aquelas verificadas para as ocorrências do MCB e do Tigrano, talvez pelos motivos apresentados anteriormente, apesar da presença das zonas anômalas 4 e 5, verificando-se o mesmo comportamento para as ocorrências Gaspar Alto e Quati (6 e 7, respectivamente, Fig. 8). Finalmente na área favorável E foi identificado apenas um pico anômalo do Parâmetro F, entre a média mais dois e mais três desvios padrão, no centro da zona 6 .

Com base na assinatura das ocorrências do MCB e do Tigrano foram propostos três novos alvos exploratórios para ouro (Fig. 11), os quais devem refletir estilos semelhantes de mineralização. O primeiro alvo (F1) localiza-se na borda do granitóide Valsungana, a nordeste da área; o segundo (F2) situa-se no granitóide Guabiruba, porção centro-leste da Folha Botuverá e o terceiro (F3) está hospedado na região de xistos da unidade MPA1 do Complexo Brusque e posicionado a oeste da ocorrência do Tigrano, possivelmente no prolongamento da mesma estrutura de direção EW.

A assinatura gamaespectrométrica do alvo F1 pode ser observada na figura $10 \mathrm{~b}$, onde destaca-se do mesmo modo que na figura 10a, incrementos da razão eU/eTh, do parâmetro $\mathrm{F}$ e das anomalias $U_{d}$ e $K_{d}$, associadas com baixas razões $T h / K$, portanto indicativas de tratos de alteração hidrotermal. É importante ressaltar que o alvo F1 encerra duas estações anômalas de $\mathrm{Au}$, além de representar os mais elevados índices do parâmetro F, do Kd e do $\mathrm{Ud}$, além das mais baixas razões $\mathrm{eTh} / \mathrm{K}$ de toda a área (ver figura 9).

CONCLUSÕES O Projeto Aerogeofísico Serra do Mar Sul pode contribuir, principalmente após as transformações feitas por BARMP (1997), tanto para o mapeamento geológico quanto à prospecção mineral. Os parâmetros $F, K_{d}$ e $U_{d}$ integrados com a geologia se mostraram eficazes no delineamento de áreas de alteração hidrotermal, podendo encerrar grande performance quando aplicados à dados de levantamentos modernos de alta resolução (espaçamento das linhas de vôo entre 50 e $250 \mathrm{~m}$ ). O tratamento dos dados gamaespectrométricos por unidades geológicas (principalmente na discriminação de granitóides), perfis empilhados com a geologia e a topografia e mapas de anomalias ao longo das linhas de vôo, por meio de geotecnologias, permitiram caracterizar melhor as assinaturas radiométricas das ocorrências e sugerir novos alvos exploratórios para ouro (e.g. F1), do que as imagens geofísicas.

Agradecimentos À Companhia de Pesquisa de Recursos Minerais (CPRM) pela cessão dos dados aerogeofísicos, geológicos e exploratórios, à CAPES pela bolsa de mestrado e a dois revisores da RBG pelas sugestões ao manuscrito. 

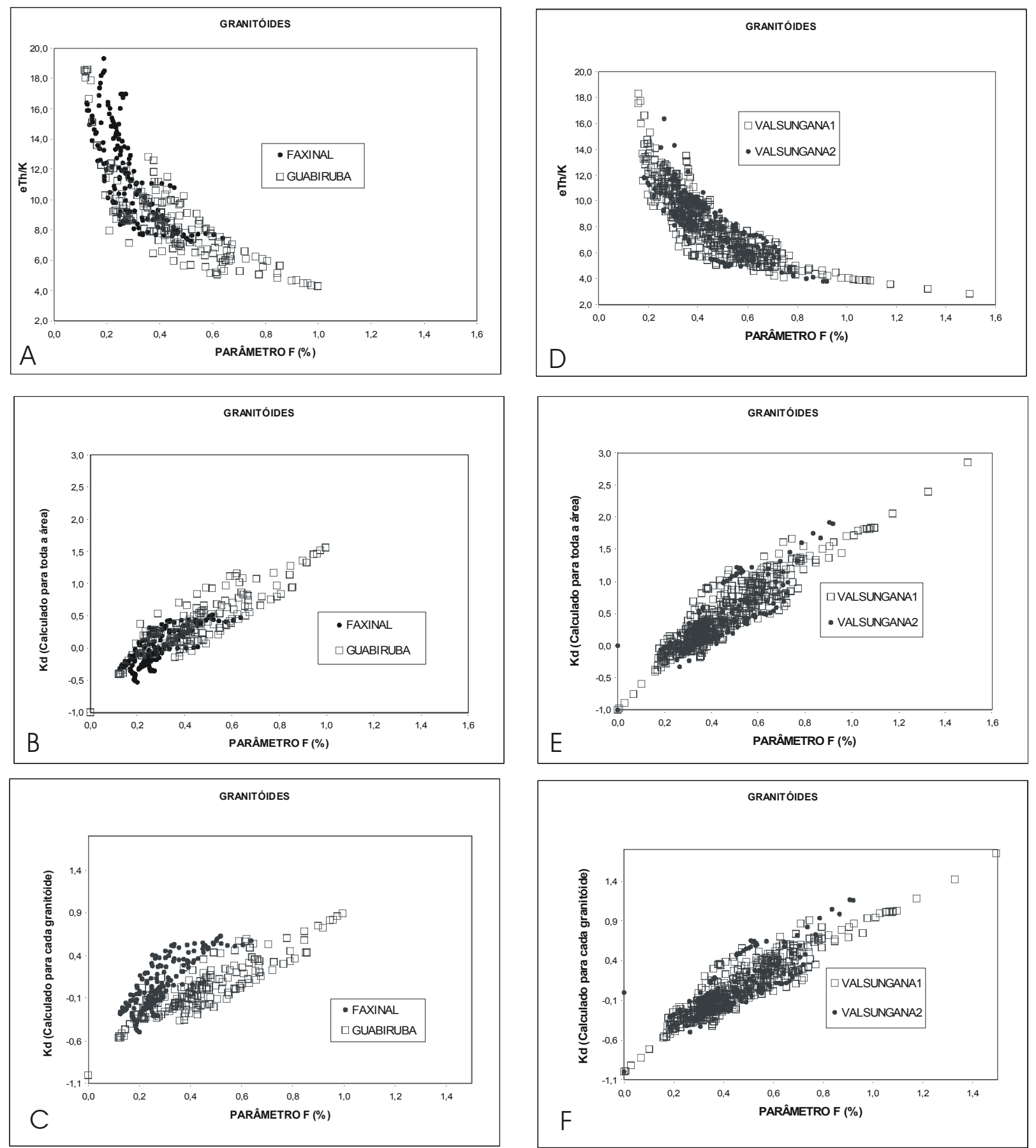

Figura 7 - Gráficos de correlação entre variáveis gamaespectrométricas para os granitóides da Folha Botuverá-SC: Faxinal x Guabiruba: eTh/K x Parâmetro $F(a) ; K_{d}$ (calculado para toda a área) x Parâmetro $F(b) ; K_{d}$ (calculado para cada granitóide) $x$ Parâmetro $F(c)$. Valsungana $1 x$ Valsubgana 2: eTh/Kx Parâmetro $F(d) ; K_{d}$ (calculado para toda a área) $x$ Parâmetro $F(e)$; $K_{d}$ (calculado para cada granitóide) $x$ Parâmetro $F(f)$.

\section{Referências}

BARMP 1997. Brazil Airborne Radiometric Mapping Project. Paterson, Grant \& Watson Limited (PGW), Companhia de Pesquisa de Recursos Minerais (CPRM) and Geological Survey of Canada (GSC), Rio de Janeiro, 18p.

Basei M.A.S. 1985. O Cinturão Dom Feliciano em Santa Catarina.
Instituto de Geociências, Universidade de São Paulo, São Paulo, Tese de Doutoramento, 190p.

Basei M.A.S. 1996. O Grupo Brusque - uma unidade em provável terreno suspeito durante o Neoproterozóico. In: SBG, Congr. Bras. Geol. 34, Salvador, Anais, p.101-104. 

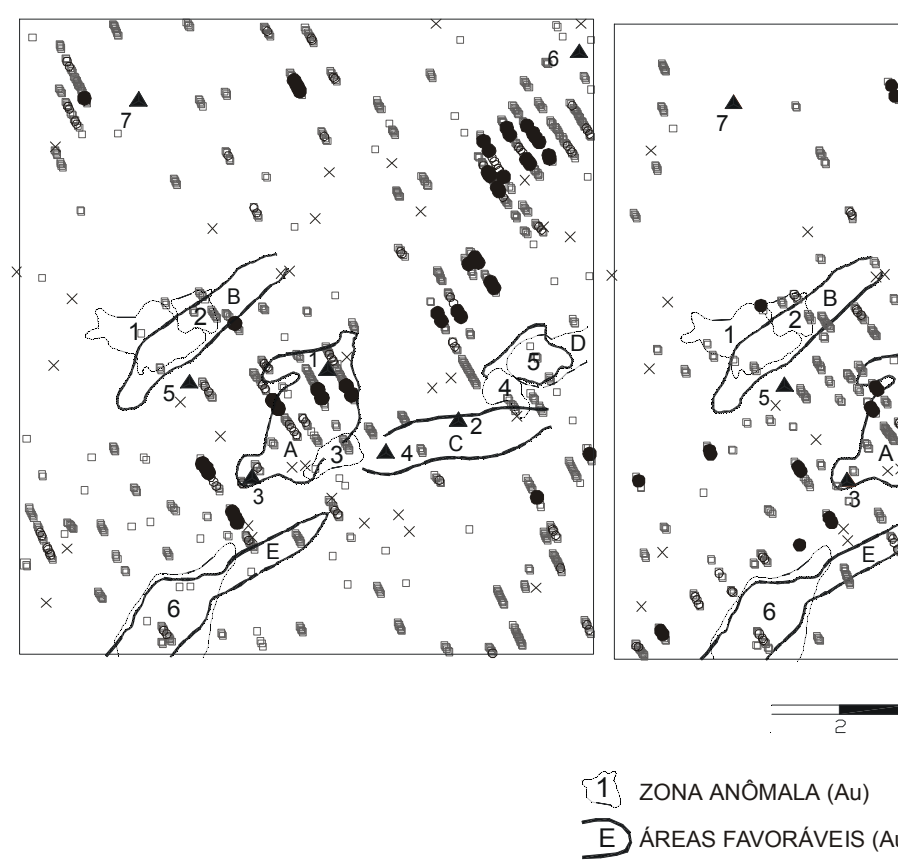

$x+1 s<\square<x+2 s \quad x+2 s$

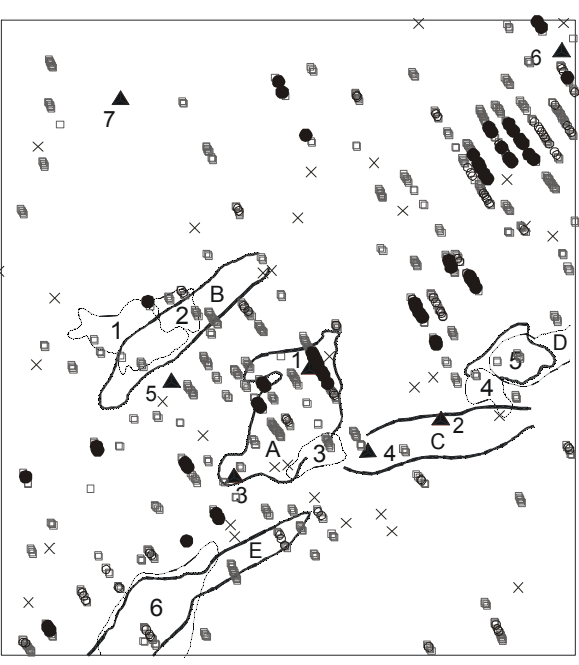

ESTAÇÃO ANÔMALA (Au) - OCORRENCIAS DE Au
EM ROCHAS

Figura 8 - Mapas de anomalias gamaespectrométricas ao longo das linhas de vôo da Folha Botuverá-SC: Parâmetro F (a); $K_{d}(b)$; $U_{d}(c)$.
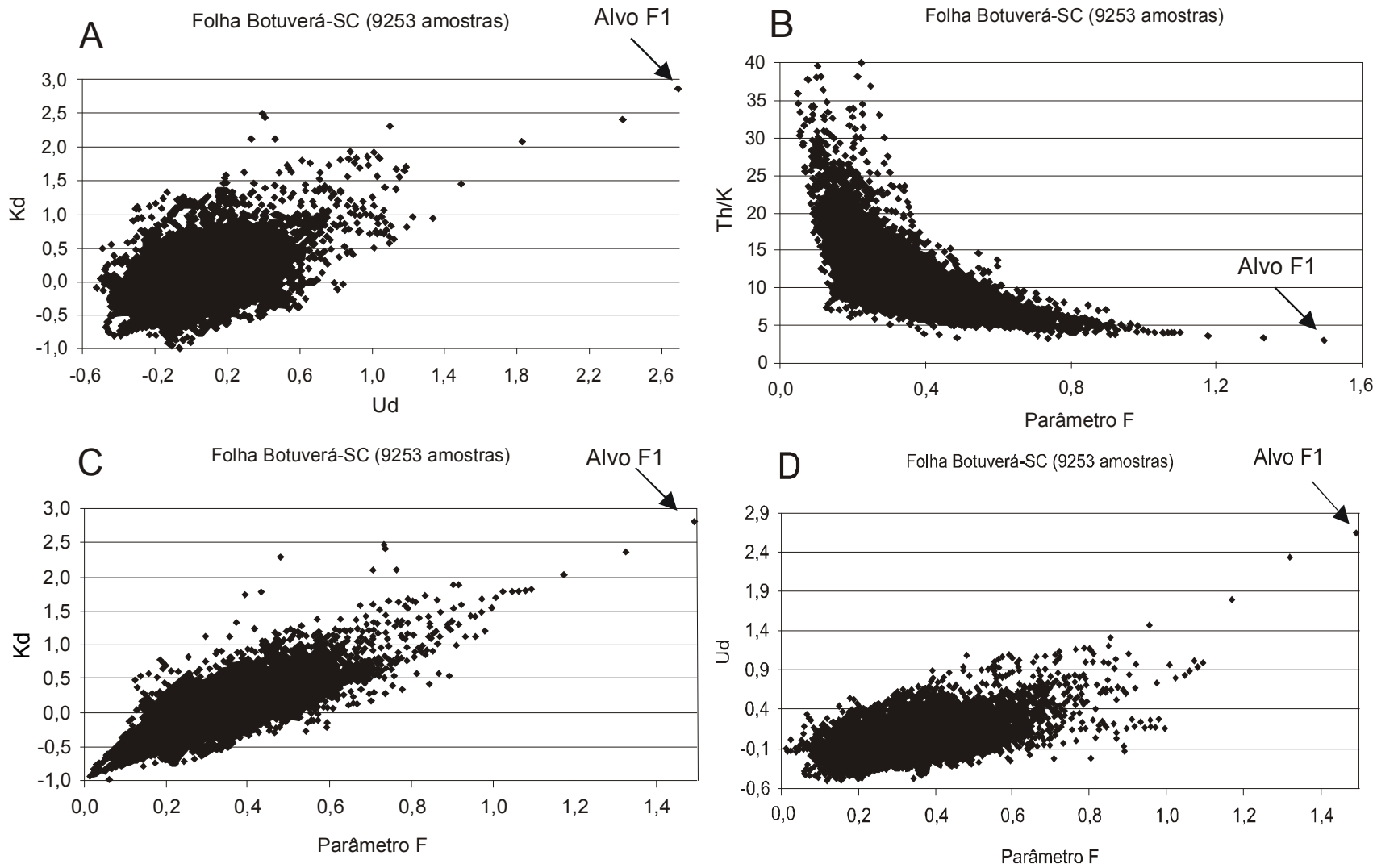

Figura 9 - Gráficos de correlação entre variáveis gamaespectrométricas da Folha Botuverá-SC indicando o alvo exploratório F1 (Fig. 11): $K_{d} x U_{d}(a)$; Th/Kx Parâmetro $F(b) ; K_{d} x$ Parâmetro $F(c) ; U_{d} x$ Parâmetro $F(d)$. 

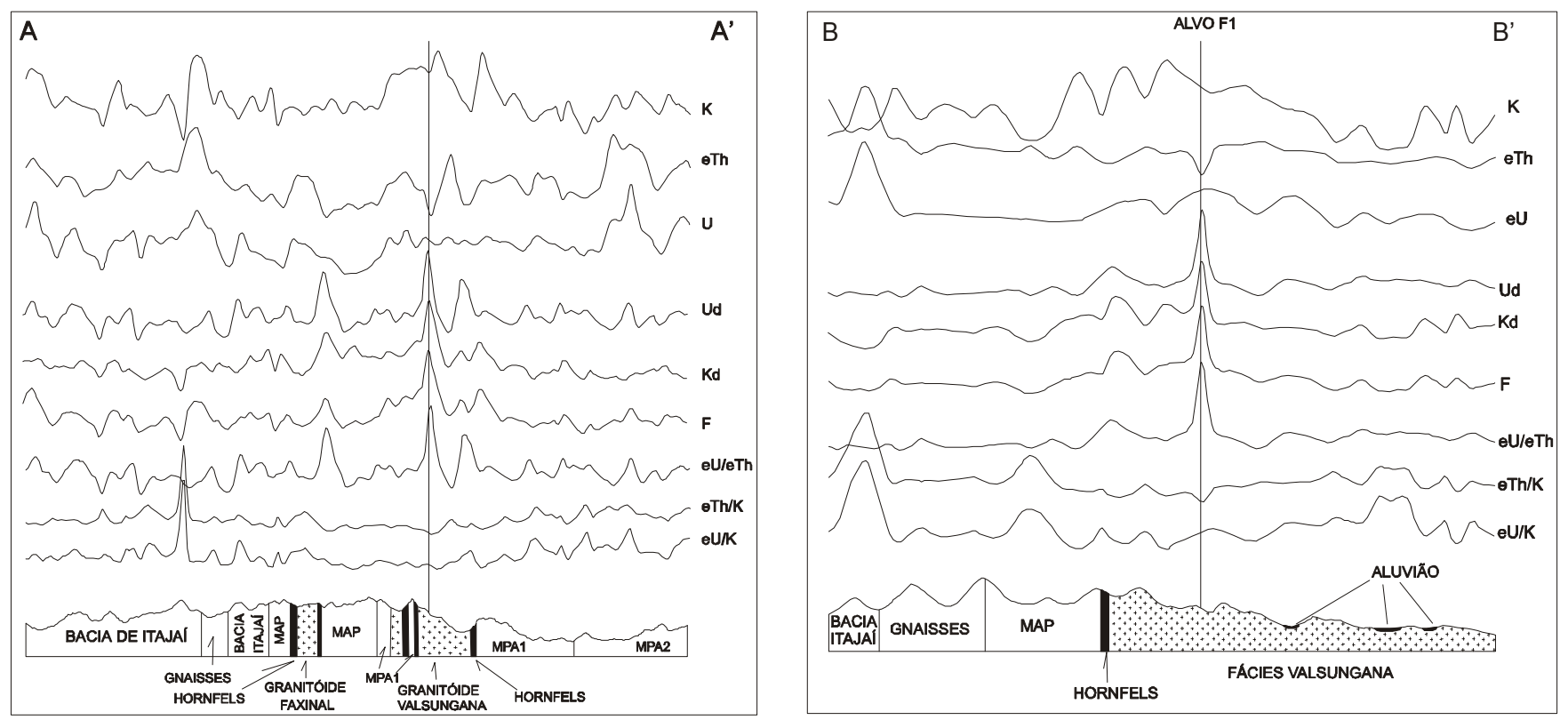

Figura 10 - Perfis gamaespectrométricos empilhados com a geologia e a topografia na Folha Botuverá-SC: Perfil A-A' (a); Perfil BB'(b). Localização dos perfis nas figuras 1 e 2.

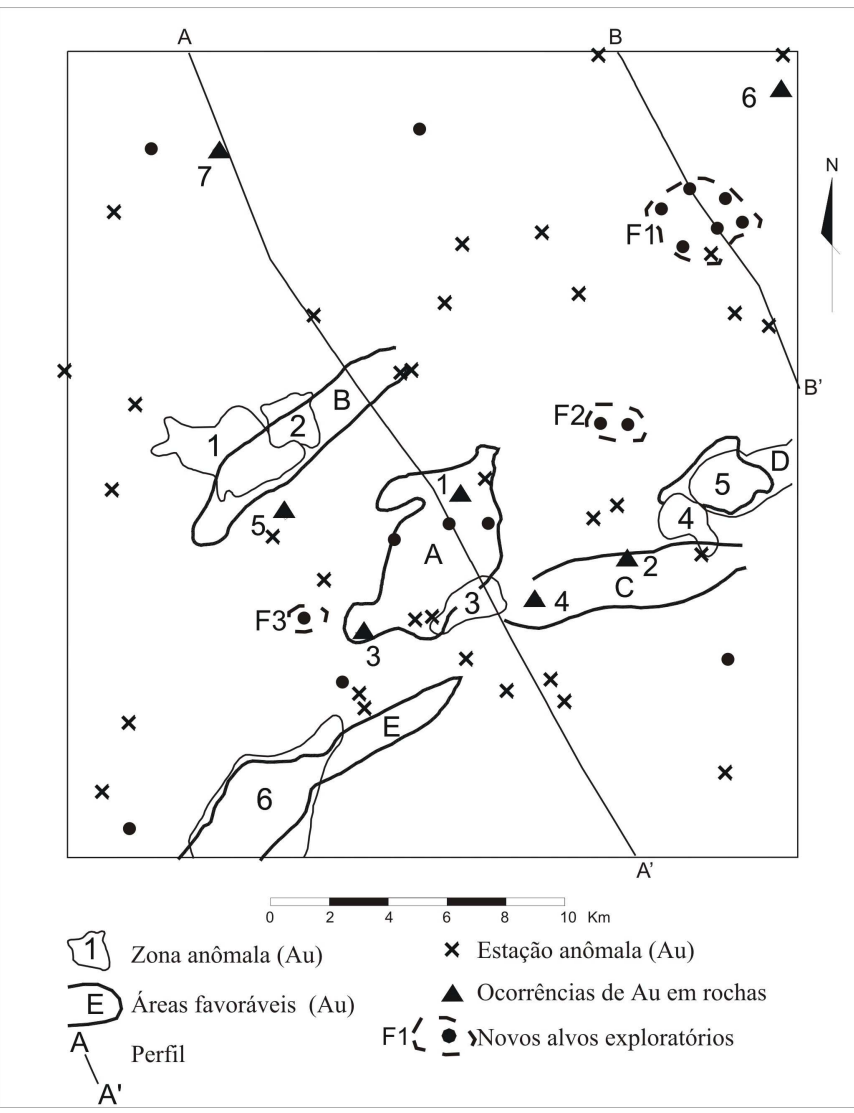

Figura 11 - Mapa de localização dos novos alvos exploratórios da Folha Botuverá-SC. Demais símbolos conforme as Figs. 2 e 8.
Basei M.A.S., Siga Jr. O., Masquelin H., Harara O.M., Reis Neto J.M., Preciozzi F.P. 2000. The Dom Feliciano belt of Brazil and Uruguay and its foreland domain, the Rio de La Plata craton: framework, tectonic evolution and correlation with similar provinces of southwestern Africa. In: Cordani U.G., Milani E.J., Thomaz Filho A., Campos D.A. Tectonic evolution of South America. Rio de Janeiro, ed. Esp. XXXI International Geological Congress, Rio de Janeiro, p.311-334.

Biondi J.C., Bartoszeck M.K., Vanzela G.A. 2001. Controles geológicos e geomorfológicos dos depósitos de caulim da Bacia de Campo Alegre (SC). Rev. Bras. Geociências, 31:13-20.

Blum M.L.B. 1999. Processamento e interpretação de dados de geofisica aérea no Brasil central e sua plicação à geologia regional e à prospecção mineral. Instituto de Geociências, Universidade de Brasília, Brasília, Tese de Doutoramento, 229p.

Briggs I.C. 1974. Machine contouring using minimumcurvature.Geophysics, 39:39-48.

Cainzos R.L.P. 2001. Integração de dados geofisicos e geológicos de Cuba centro-oriental: contribuições à cartografia e exploração mineral regional. Instituto de Geociências, Universidade Estadual de Campinas, Campinas, Tese de Doutoramento, 253p.

Caldasso A.L.S., Krebs A.S.J., Silva M.A.S., Camozzato E., Ramgrab G.E. 1995. Programa Levantamentos Geológicos Básicos do Brasil, Folha Botuverá (SG.22-Z-D-I-2), 1:50.000, Estado de Santa Catarina, Brasília-DF.

Carvalho M.T.N. Integração de dados geológicos, geofísicos e geoquímicos aplicados à prospecção de ouro nos greenstone belts de Pilar de Goiás e Guarinos, GO. Instituto de Geociências, Universidade de Brasília, Brasília, Dissertação de Mestrado, 229p.

Castro N.A. 1997. Contribuição ao conhecimento geológicometalogenético associado aos granitóides intrusivos no Grupo Brusque (SC) com base em informações geológicas, aerogamaespectrométricas e Landsat/TM-5. Instituto de Geociências, Universidade Estadual de Campinas, Campinas, Dissertação de Mestrado, 229p. 
Castro N.A., Crósta. A.P., Ferreira F.J.F., Basei M.A.S., Pascholati M.E. 2003. Quadro geológico regional da porção central do embasamento pré-Ordoviciano de Santa Catarina com base em imagens Landsat-5/ TM e aerogeofísica. Rev. Bras. Geoc.(neste volume).

CPRM 1978. Projeto Aerogeofisico Serra do Mar Sul. CPRM/GEOFOTO (arquivo digital), Rio de Janeiro.

Dickson B.L. \& Scott K.M. 1997. Interpretation of aerial gamma-ray surveys - adding the geochemical factors. In: Airborne Magnetic and Radiometric Surveys, AGSO Journal of Australian Geology \& Geophysics, 17:187-200.

Ferreira F.J.F. 1991. Aerogamaespectrometria e aeromagnetometria de um trato ocidental do Pré-cambriano paulista. Instituto de Geociências, Universidade de São Paulo, São Paulo, Tese de Doutoramento, $150 \mathrm{p}$.

Ferreira F.J.F. \& Algarte J.P. 1979. O comportamento aeromagnetométricocintilométrico das principais rochas alcalinas dos estados de São Paulo e Paraná. In: SBG, Simp. Reg. Geol., 2, Rio Claro, Atas, p.195208.

Ferreira F.J.F., Franke N.D., Silva F.V., Forlin M. 1998. Identificação gamaespectrométrica de áreas de alteração hidrotermal na região de Peixoto de Azevedo - MT. In: SBG, Congr. Bras. Geol., 40, Belo Horizonte, Anais, 1:332.

Ferreira F.J.F. \& Stevanato R. 1998. Proposta de agrupamento de domínios gamaespectrométricos aplicada ao mapeamento geológico e à prospecção mineral. In: SBG, Congr. Bras. Geol., 40, Belo Horizonte, Anais, 1:328.

Ferreira F.J.F. \& Silva F.V. 1999. Integração geofísico-geológica da Folha Curitiba-PR. In: SBGf, International Congress of the Brazilian Geophysical Society, 6, Rio de Janeiro, Proceedings, CD-ROM.

Fornazzari Neto L., Ferreira F.J.F., Forlin M. 1996. Integração geofísicogeológica da região de Tunas-Perau, PR. In: SBG, Congr. Bras. Geol., 39, Salvador. Anais, 2:382-384.

Fornazzari Neto L., Ferreira F.J.F., Campos A.F. $2001 \mathrm{a}$. Gamaespectrometria aplicada à prospecção de ouro na Folha Botuverá-SC. In: SBGf, International Congress of the Brazilian Geophysical Society, 7, Salvador, Proceedings, CD-ROM.

Fornazzari Neto L., Ferreira F.J.F., Forlin M., Rostirolla S.P. 2001b. Gamaespectrometria da ocorrência de ouro do Morro do Carneiro Branco - SC. In: SBGf, International Congress of the Brazilian Geophysical Society, 7, Salvador, Proceedings, CD-ROM.

Fragoso-Cesar A. R. S. 1980. O Cráton Rio de La Plata e o Cinturão Dom Feliciano no Escudo Sul-riograndense. In: SBG, Cong. Bras. Geol., 31, Balneário Camboriú, 1980. Anais, p. 2879-2892.

Gnojek I. \& Prichystal A. 1985. A new zinc mineralization detected by airborne gamma-ray spectrometry in northern Moravia (Czechoslovakia). Geoexploration, 23:491-502.

Graham D.F. \& Bonham-Carter G.F. 1993. Airborne radiometric data: a tool for reconnaissance geological mapping using a GIS. Photogrammetric Engineering \& Remote Sensing, 59(8):1243-1249.

Hasui Y., Carneiro C.D.R., Coimbra A.M. 1975. The Ribeira Folded Belt. Rev. Bras. Geociências, 5:257-266.

Hoover D.B. \& Pierce H.A. 1990. Annotated Bibliography of GammaRay Methods Applied to Gold Exploration. USGS Open-File Report, p.90-203.

IBGE 1974. Folha Botuverá (SG-22-Z-D-I-2) escala 1:50.000. Instituto Brasileiro de Geografia e Estatística - IBGE, Rio de Janeiro, Brasil.

Luyendky A.P.J. 1997. Processing of airborne magnetic data. In: Airborne
Magnetic and Radiometric Surveys, AGSO Journal of Australian Geology \& Geophysics, 17:31-38.

Minty B.R.S. 1991. Simple micro-levelling for aeromagnetic data. Exploration Geophysics, 22:591-592.

Nabi S.H.A.E. 1995. Statistical evaluation of airborne gamma-ray spectrometric data from the Magal Gebriel area, south Eastern Desert, Egypt. Journal of Applied Geophysics, 34:47-54.

Ostrovsky E.A. 1975. Antagonism of radioactive elements in wallrock alteration fields and its use in aerogamma spectrometric prospescting. International Geology Review, 17:461-468.

Pascholati E.M. 1990. Caracterização geofisica da Suite Intrusiva de Itu. Instituto Astronômico e Geofísico, Universidade de São Paulo, São Paulo, Tese de Doutoramento, 135p.

Pirajno F. 1992. Hydrothermal Mineral Deposits - Principles and Fundamental Concepts for the Exploration Geologist. New York, SpringerVerlag, $784 \mathrm{p}$.

Pires A.C.B. 1995. Identificação geofísica de áreas de alteração hidrotermal, Crixás-Guarinos, Goiás. Rev. Bras. Geociências, 25:61-68.

Quadros T.F.P. 2000. Integração de dados em ambiente SIG para mapeamento de favorabilidade mineral de ouro na Ilha Cristalina de Riviera (Uruguai). Escola de Engenharia, Universidade Federal do Rio Grande do Sul, Porto Alegre, Tese de Doutoramento, 259p.

Saunders D.F., Terry S.A., Thompson C.K. 1987. Test of National Uranium Resource Evaluation gamma-ray spectral data in petroleum reconnaissance. Geophysics, 52:1547-1556

Shives R.B.K., Charnonneau B.W., Ford K.L. 2000. The detection of potassic alteration by gamma-ray spectrometry - Recognition of alteration related to mineralization. Geophysics, 65:2001-2011.

Silva F.V. 1999. Integração gamaespectrométrica-geológica da Folha Curitiba-PR. Departamento de Geologia, Curso de Pós-Graduação em Geologia Exploratória, Universidade Federal do Paraná, Curitiba, Dissertação de Mestrado, 204p.

Silva D.C. \& Mantovani M.S.M. 1994. Projeto Aerogeofísico Serra do Mar Sul: uma abordagem semi-quantitativa. Rev. Bras. Geociências, 24:120-127.

Soares P.C. 1988. Tectônica colisional em torno do Bloco Paraná, Brasil. In: Cong. Latino-Amer. Geol., 7, Belém, Anais, 1:63-79.

Soares P.C., Fiori A.P., Carmignani L., Rostirolla S.P. 2000. A geotectonic view of the Ribeira and Dom Feliciano belts. Rev. Bras. Geociências, 30: 130-134.

Stevanato R. 1998. Modelo exploratório para depósitos de chumbo e zinco na Faixa Itaiacoca - PR/SP. Departamento de Geologia, Curso de Pós-Graduação em Geologia Exploratória, Universidade Federal do Paraná, Curitiba, Dissertação de Mestrado, 205p.

Vasconcellos R.M., Da Vinha C.A.G., Orlandi Filho V., Azevedo M.L.V. 1990. Análise de agrupamento em dados aerogeofísicos: um exemplo de aplicação para levantamentos geológicos básicos. In: SBG, Congr. Bras. Geol., 36, Natal, Resumos.

Wilford J.R., Bierwirth P.N., Craig M.A. 1997. Application of airborne gamma-ray spectrometry in soil/regolith mapping and applied geomorphology. In: Airborne Magnetic and Radiometric Surveys, AGSO Journal of Australian Geology \& Geophysics, 17:201-216.

Manuscrito SR-28

Recebido em 22 de novembro de 2003

Revisão dos autores em 06 de março de 2003

Revisão aceita em 20 de abril de 2003 